\title{
Mass Spectrometric Investigation of the Chemical Composition of Caramel Formed upon Heating of Disaccharides
}

\author{
Agnieszka Golon and Nikolai Kuhnert \\ School of Engineering and Science, Jacobs University Bremen, Bremen 28759, Germany
}

Received: May 22, 2012 / Published: November 20, 2012.

\begin{abstract}
Disaccharides are a very important group of carbohydrates, being main components of many daily food products. The heating of these biomolecule causes the formation of caramel, an extremely complex material. The dominant fraction of non-volatile compounds, responsible for both color and flavor of food products, has been studied on a few occasions. Herein, the composition of caramels obtained by heating of sucrose, lactose and maltose were studied using combined mass spectrometry techniques. High resolution electrospray mass spectrometry was applied followed by targeted multi-stage LC-tandem mass spectrometry $\left(\right.$ ESI-MS $\left.^{\mathrm{n}}\right)$ and MALDI-MS. Novel graphical interpretation strategies such as van Krevelen and Kendrick mass analysis have been applied to study the composition of caramels. Products of caramel include oligomerization, depolymerization, hydration and dehydration products. Oligomers with up to eight carbohydrate units and dehydrated oligomers losing up to eight water molecules have been identified.
\end{abstract}

Key words: Browning, caramelization, carbohydrates, disaccharides, sucrose, complex mixtures, mass spectrometry.

\section{Introduction}

Heating of mono and disaccharides by thermal food processing generates the brown color and pleasurable aroma of caramel $[1,2]$. Thermally processed sugars are consumed at an estimated level of $50 \mathrm{Mt}$ annually, thus representing one of mankind most important dietary materials [3]. Despite its importance, the detailed chemical composition of non-volatile fraction, corresponding to around $98 \%$ of its dry weight, has remained largely mysterious, mainly due to its high complexity. Several studies have been carried out on melting, thermodynamic properties of disaccharides [4-7] and demonstrate an enhanced interest in the chemistry of heated carbohydrates.

Caramels have been analyzed particularly by gas chromatography/mass spectrometry focusing on volatile compounds such as hydroxymethylfurfural

\footnotetext{
Corresponding author: Nikolai Kuhnert, professor, research field: analytical chemistry. E-mail: n.kuhnert@jacobs-university.de.
}

(HMF) and hydroxyacetylfuran (HAF), hydroxydimethylfuranone (HDF), dihydroxydimethylfuranone (DDF), maltol and hydroxymaltol [8-10]. The volatile compounds formed in caramelization have been investigated comprehensively, whereas the chemistry of non-volatile components has been studied only on a few occasions [11, 12]. The reaction products of caramelization were classified into three particular classes: Caramelans-Tetramers of hexoses $\left(\mathrm{C}_{24} \mathrm{H}_{36} \mathrm{O}_{18}\right)$, Caramelens-Hexamers of glucose $\left(\mathrm{C}_{36} \mathrm{H}_{50} \mathrm{O}_{25}\right)$ and Caramelins-Polymers of glucose $\left(\mathrm{C}_{125} \mathrm{H}_{188} \mathrm{O}_{80}\right)$ [13]. That classification exists without any further structure suggestions due to the complexity of created products during caramelization. Mass spectrometry (MS) has been applied for structural investigation of saccharides, using mainly electrospray ionization (ESI) [14-16] and matrix-assisted laser desorption/ionization (MALDI) [17-19]. Tandem mass spectrometry (MS/MS) is demonstrated to be a valuable tool in the structural 
characterization of carbohydrates to achieve thorough information regarding their structure [20,21].

We have recently reported on the application of novel mass spectrometry strategies for the characterization of caramel obtained from glucose and fructose. Following these reports, we report here on the characterization of caramel products obtained from disaccharides. We aim to unravel the complexity of caramel, formed when these carbohydrates are heated. The most dietary relevant disaccharides are sucrose (or saccharose) $[22,23]$, lactose a reducing disaccharide abundant in milk and dairy products and maltose, present in malt and beer. While heating of sucrose produces classical caramel used in traditional cooking, baking and as food additive for coloring of beverages or baking goods, heating of lactose occurs frequently in traditional baking recipes with added dairy products or the production of the Hispanic "dulce de leche" and maltose is heated prior to traditional beer brewing. In this study, we applied the novel graphical interpretation strategies such as Kendrick and van Krevelen for complex mass spectrometric data of caramels. These data interpretation techniques have visualized wide spectrum of the product formed during caramelization process and led to more specify characterization.

\section{Materials and Methods}

Solvents (analytical grade) and all chemicals were purchased from Sigma-Aldrich (Bremen, Germany).

\subsection{Sample Preparation}

All sugar samples $(1 \mathrm{~g})$ were heated in an oven for 2 $\mathrm{h}$ at $180{ }^{\circ} \mathrm{C}$ (sucrose, maltose) and at $200{ }^{\circ} \mathrm{C}$ (lactose). The heated samples were stored at room temperature. Heated carbohydrates $(1 \mathrm{mg})$ were dissolved in methanol/water $(1: 1, \mathrm{v} / \mathrm{v}, 1 \mathrm{~mL})$ and directly used for micrOTOF and direct infusion ION TRAP.

\subsection{High Resolution MS}

Bruker Daltonics micrOTOF instrument from methanolic/water solutions were used for high resolution mass spectra, employing the negative and positive electrospray ionization mode. MicrOTOF focus mass spectrometer (Bruker Daltonics) fitted with an ESI source and internal calibration was achieved with $10 \mathrm{~mL}$ of $0.1 \mathrm{M}$ sodium formate solution. Calibration was carried out using the enhanced quadratic calibration mode. All MS measurements were performed in the negative and positive ion mode. It should be noted that the intensities of the measured peaks in a TOF calibration influenced the magnitude of the mass error with high-intensity peaks resulting in detector saturation displaying larger mass errors. Usually this problem can be overcome by using spectra averaging on the side flanks of a chromatographic peak or by taking more diluted samples.

\subsection{Data Analysis}

Molecular formulas were calculated using Bruker software Data Analysis 4.0. Data was subsequently exported to Excel to carry out simple mathematical operation such as determination of $\mathrm{H} / \mathrm{C}$ and $\mathrm{O} / \mathrm{C}$ ratios or Kendrick analysis. All graphs were created using Origin 7.5.

\subsection{LC-MS}

The LC equipment (Agillent 1100 series, Bremen, Germany) comprised a binary pump, an auto sampler with a $100 \mu \mathrm{L}$ loop, and a DAD detector with a light-pipe flow cell (recording at 320 and $254 \mathrm{~nm}$ and scanning from 200 to $600 \mathrm{~nm}$ ). This was interfaced with an ion-trap mass spectrometer fitted with an ESI source (Bruker Daltonics HCT Ultra, Bremen, Germany) operating in an Auto $\mathrm{MS}^{\mathrm{n}}$ mode to obtain fragment ion $m / z$. As necessary, $\mathrm{MS}^{2}, \mathrm{MS}^{3}$, and $\mathrm{MS}^{4}$ fragment-targeted experiments were performed to focus only on compounds producing a parent ion at $\mathrm{m} / \mathrm{z}$ $143,161,179,197,287,305,323,341,359,449,431$, 467, 485, 503, 521, 611, 629, 647, 665, 683, 773, 791, 809,827 and 845 . Tandem mass spectra were acquired in an Auto-MS ${ }^{n}$ mode (smart fragmentation) using a ramping of the collision energy. Maximum 
fragmentation amplitude was set to $1 \mathrm{~V}$, starting at $30 \%$ and ending at 200\%. MS operating conditions (negative mode) have been optimized using glucose with a capillary temperature of $365^{\circ} \mathrm{C}$, a dry gas flow rate of $10 \mathrm{~L} / \mathrm{min}$ and a nebulizer pressure of $12 \mathrm{psi}$.

\subsection{HPLC}

Separation was achieved on a $250 \times 4.6 \mathrm{~mm}$ i.d. column containing diphenyl $5 \mu \mathrm{m}$ and $5 \times 4.6 \mathrm{~mm}$ i.d. guard column of the same material (Varian, Darmstadt, Germany). Solvent (water/formic acid 1000:0.05 v/v) was delivered at a total flow rate of $850 \mu \mathrm{L} / \mathrm{min}$ by 25 min isocratic.

\subsection{MALDI-TOF-MS}

All experiments were performed in the positive ion mode using an Ultraflex II MALDI TOF/TOF mass spectrometer (Bruker Daltonics, Bremen) equipped with a pulsed $50 \mathrm{~Hz} \mathrm{~N}$ laser (wavelength $337 \mathrm{~nm}$ ). Laser intensity was varied in the range from $30 \%$ to $45 \%$. Sample $(0.5 \mu \mathrm{L})$ was deposed on top of a layer of crystals of 2,5-dihydroxybenzoic acid (DHB) formed by decomposition of $0.5 \mu \mathrm{L}$ of DHB solution on the MALDI plate and allowing it dry at ambient temperature. A MALDI matrix was prepared by dissolving $5 \mathrm{mg}$ of DHB in $1 \mathrm{~mL}$ mixture of acetonitrile/methanol/aqueous trifluoroacetic acid $(1 \%, \mathrm{v} / \mathrm{v})(1: 1: 1, \mathrm{v} / \mathrm{v} / \mathrm{v})$.

\subsection{Thermogravimetric Analysis (TGA)}

TGA were performed using a TA instruments SDT Q600 instrument. The temperature was ramped from 25 to $180{ }^{\circ} \mathrm{C}$ for sucrose, maltose and to $200{ }^{\circ} \mathrm{C}$ for lactose at a rate of $5{ }^{\circ} \mathrm{C} / \mathrm{min}$ and kept at final temperature for $2 \mathrm{~h}$ using a nitrogen atmosphere.

\subsection{Infrared (IR) Analysis}

Infrared spectra were recorded on $\mathrm{KBr}$ pellets using a Nicolet Avatar 370 spectrometer.

\section{$2.9^{1} H N M R$}

${ }^{1} \mathrm{H}$ NMR spectra were acquired on a JEOL ECX-400 spectrometer operating at $400 \mathrm{MHz}$, at room temperature in $\mathrm{D}_{2} \mathrm{O}$, using a $5 \mathrm{~mm}$ probe. The chemical shifts $(\delta)$ are reported in parts per million (ppm).

\section{Results and Discussion}

The chemical composition of the non-volatile fraction of caramel is largely unknown due to its complexity combined with a lack of analytical strategies so far able to characterize extremely complex material comprising several thousand individual components. Modern LC-mass spectrometry combines the best of four worlds, ultra high resolution combined with high sensitivity, high selectivity due to targeted ion isolation and isomer separation based on LC-techniques. These features allow finally a chemically meaningful analysis of processed food materials.

In this contribution, we characterize the products obtained by thermal processing from [a space deleted] the three dietary most relevant disaccharides sucrose 1 , maltose 2 and lactose 3 using a recently developed approach called domino tandem mass spectrometry, in which high resolution direct infusion MS data are acquired and interpreted yielding several structural hypothesis, one of which is in a second step (therefore domino) is confirmed by targeted LC-tandem MS experiments.

In term to find the optimized heating conditions for further analysis, the mass spectra were recorded for samples obtained at different temperatures. The studied samples were thus heated from room temperature until $180{ }^{\circ} \mathrm{C}$ for sucrose and maltose, until $200{ }^{\circ} \mathrm{C}$ for lactose and were subsequently kept for $2 \mathrm{~h}$ at the final temperature. Thermogravimetric curves showed around $10 \%-12 \%$ weight loss, which statistically correspond to one water molecule per monosaccharide. Heating procedures caused the formation of brown color, which was observed during the roasting procedure of coffee beans or heating of sugar-rich food products [24]. It is worthy to mention that heating procedure caused melting of sucrose and maltose, while lactose remained solid. So we decided to carry 
out further characterization work using these aforementioned conditions.

Mass spectrometric data were obtained in both negative and positive ion modes from caramelized sucrose (1), maltose (2) and lactose (3). Fig. 1 illustrates mass spectra of all three disaccharides in the negative ion mode. Mass spectra in the positive ion mode were dominated by sodiated molecular ions. In Table 1, the mass/charge ratio $(\mathrm{m} / \mathrm{z})$ of the product ions, elemental composition and average mass error for caramelized sucrose as the representative disaccharides are presented (positive mode data and further signal assignments are provided in the supplementary information). The exploration of mass spectra of caramelized disaccharides indicated mostly oligomerization, dehydration and hydration reactions of carbohydrates. Oligomers of disaccharides are present with up to hexamers, dehydration products of those oligomers, hydration and some redox disproportionation reaction products. Furthermore, the decomposition of oligomers to monomers appeared with the formation of their dehydrated products. Subsequently, MALDI-MS techniques were applied to observe a possible forming of further oligomers. The
MALDI spectrum with DHB (2,5-dihydroxybenzoic acid) of caramelized sucrose was recorded and resulting oligomers up to octamer at $\mathrm{m} / \mathrm{z}$ 1,337.6. Among them, hydrated and dehydrated ions have been observed which consequently confirm the results obtained with electrospray ionization technique.

\subsection{Chemometric Data Interpretation}

Novel graphical mass spectrometric data interpretation strategies might be applied to the complex mixture as is caramel. The van Krevelen and Kendrick type of analyses, first time used by petroleum researchers [25], were employed to caramelized disaccharides. These techniques visualized complex data and were used as the inspiration for further characterization of particular groups of the compounds. The aforementioned graphical techniques have been utilized only for dietary materials, such as wine [26], black tea thearubigins [27, 28] and caramel [29]. The van Krevelen diagrams constructed with the atomic ratios of $\mathrm{H} / \mathrm{C}$ and $\mathrm{O} / \mathrm{C}$ were calculated from the list with molecular formulas of the high resolution mass data of caramelized carbohydrates, as shown in Fig. 2. Different groups of the compounds have typical atomic

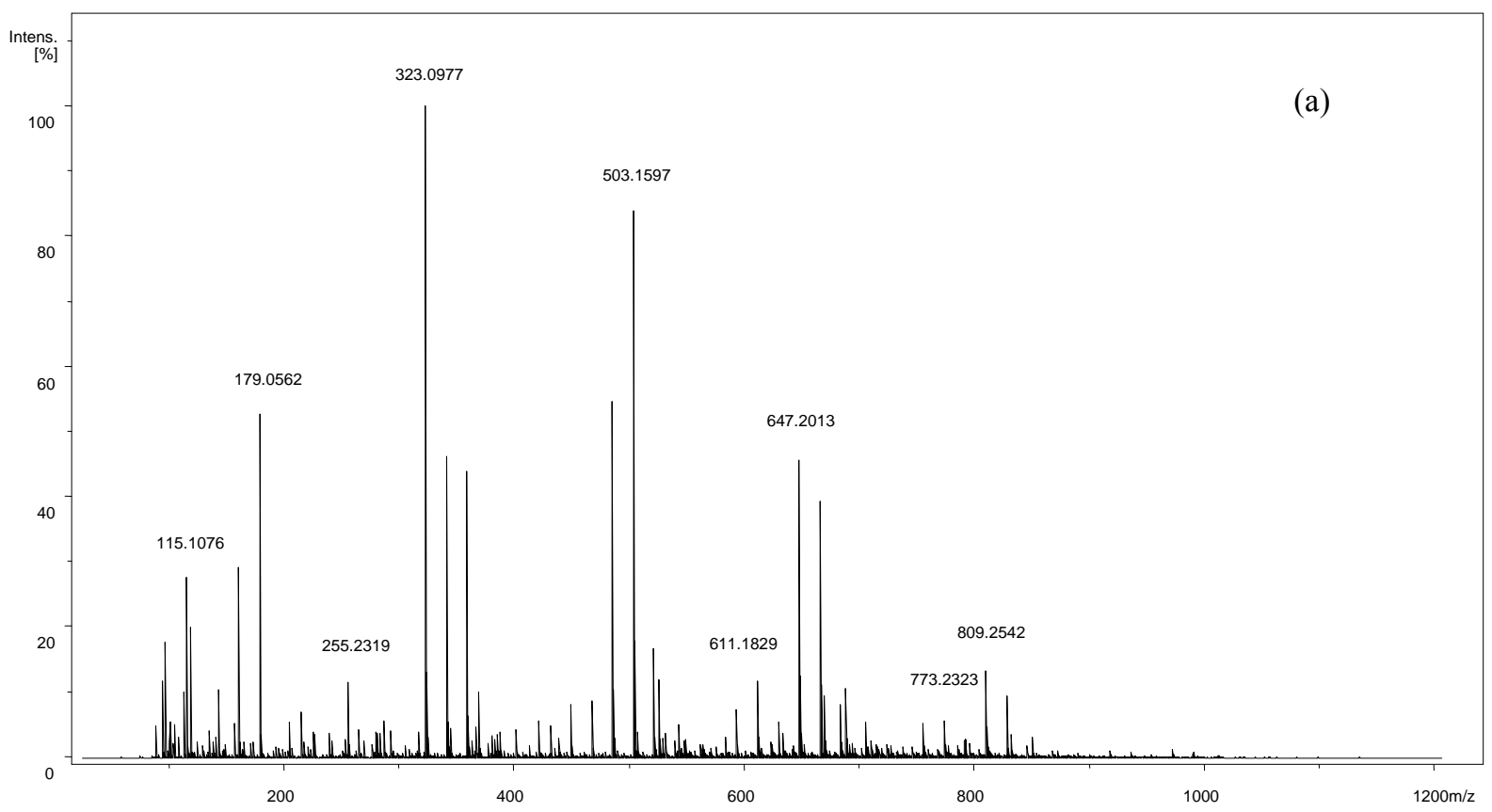



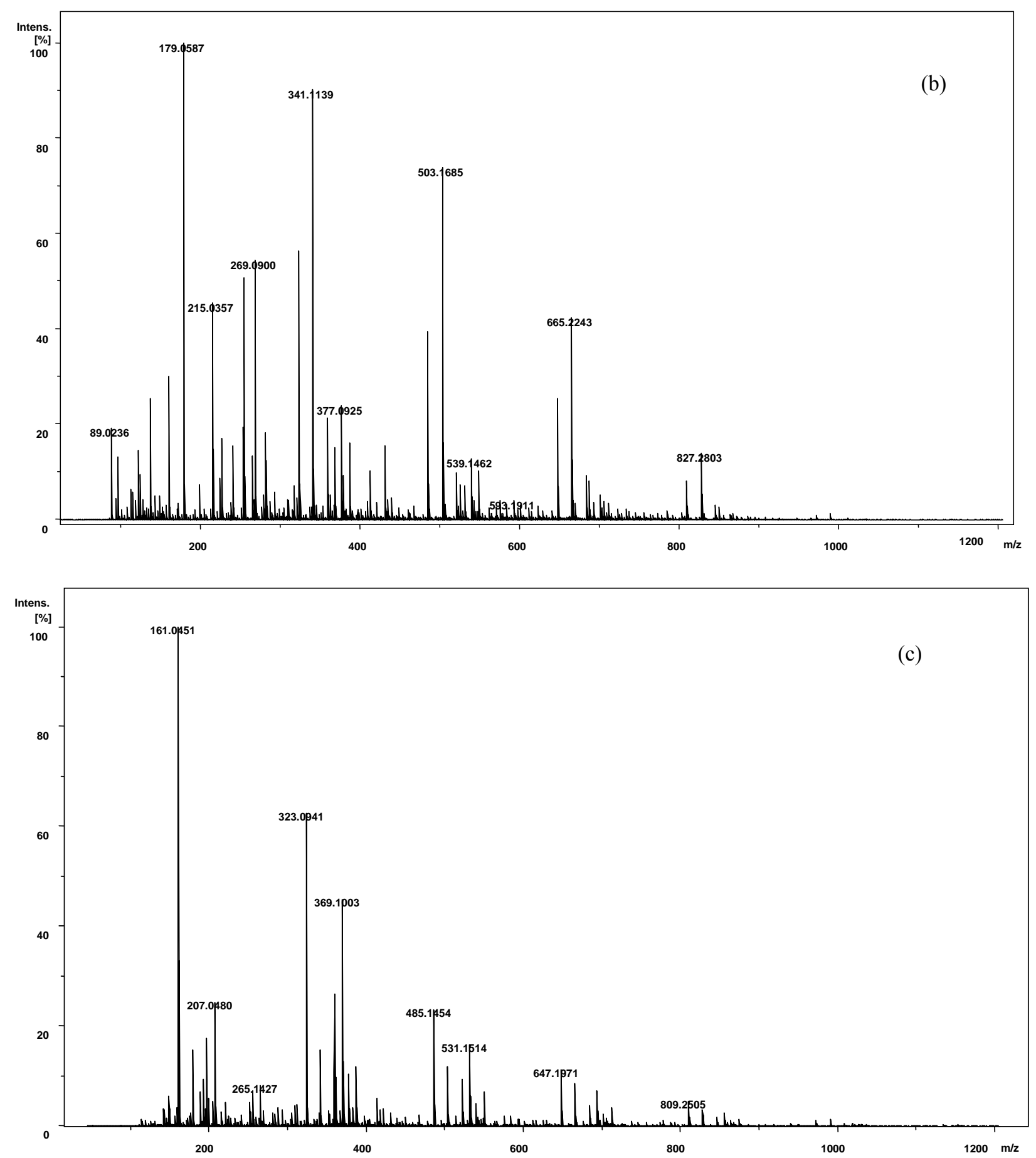

Fig. 1 Mass spectra of caramelized (a) sucrose, (b) maltose and (c) lactose in the negative ion mode using a direct infusion into an ESI-TOF-MS instrument.

ratios and consequently appear at characteristic area of the plot [30], for example, the atomic ratios for carbohydrates are $\mathrm{H} / \mathrm{C}-2$ and $\mathrm{O} / \mathrm{C}-1$. The profiles of figures for 1,2 and 3 are similar and the following groups of the compounds were found.
The group I represents the points characteristic for carbohydrates. The points in the middle of the graphs belong to dehydrated products (II). The products of disproportionation redox reactions are present in the upper left corner (III). The group of the points in the 
Table 1 High resolution mass (MS-TOF) data of caramelized sucrose and their parent ions (M-H) in the negative ion mode.

\begin{tabular}{|c|c|c|c|c|c|}
\hline Peak numbering & Assignment & Mol. formula & Experimental $m / z(\mathrm{M}-\mathrm{H})^{-}$ & $\begin{array}{l}\text { Theoretical } \mathrm{m} / \mathrm{z} \\
(\mathrm{M}-\mathrm{H})^{-}\end{array}$ & Relative error (ppm) \\
\hline 1 & & $\mathrm{C}_{6} \mathrm{H}_{12} \mathrm{O}_{2}$ & 115.0765 & 115.0765 & 0.1 \\
\hline 2 & & $\mathrm{C}_{4} \mathrm{H}_{8} \mathrm{O}_{4}$ & 119.0351 & 119.0350 & 1.4 \\
\hline 3 & & $\mathrm{C}_{8} \mathrm{H}_{16} \mathrm{O}_{2}$ & 143.1081 & 143.1078 & 2.2 \\
\hline 4 & & $\mathrm{C}_{9} \mathrm{H}_{18} \mathrm{O}_{2}$ & 157.1226 & 157.1234 & 4.9 \\
\hline 5 & Glu- $\mathrm{H}_{2} \mathrm{O}$ & $\mathrm{C}_{6} \mathrm{H}_{10} \mathrm{O}_{5}$ & 161.0461 & 161.0455 & 3.5 \\
\hline 6 & Gluor Fru & $\mathrm{C}_{6} \mathrm{H}_{12} \mathrm{O}_{6}$ & 179.0562 & 179.0561 & 0.3 \\
\hline 7 & & $\mathrm{C}_{14} \mathrm{H}_{28} \mathrm{O}_{2}$ & 227.2010 & 227.2017 & 3.0 \\
\hline 8 & & $\mathrm{C}_{15} \mathrm{H}_{30} \mathrm{O}_{2}$ & 241.2164 & 241.2173 & 3.6 \\
\hline 9 & & $\mathrm{C}_{16} \mathrm{H}_{32} \mathrm{O}_{2}$ & 255.2324 & 255.2330 & 2.2 \\
\hline 10 & & $\mathrm{C}_{15} \mathrm{H}_{22} \mathrm{O}_{4}$ & 265.1448 & 265.1445 & 1.1 \\
\hline 11 & & $\mathrm{C}_{18} \mathrm{H}_{36} \mathrm{O}_{2}$ & 283.2629 & 283.2643 & 4.8 \\
\hline 12 & & $\mathrm{C}_{12} \mathrm{H}_{16} \mathrm{O}_{8}$ & 287.0767 & 287.0772 & 2.0 \\
\hline 13 & & $\mathrm{C}_{17} \mathrm{H}_{26} \mathrm{O}_{4}$ & 293.1756 & 293.1758 & 0.8 \\
\hline 14 & Glu-Fru- $2 \times \mathrm{H}_{2} \mathrm{O}$ & $\mathrm{C}_{12} \mathrm{H}_{18} \mathrm{O}_{9}$ & 305.0866 & 305.0878 & 3.9 \\
\hline 15 & Glu-Fru- $\mathrm{H}_{2} \mathrm{O}$ & $\mathrm{C}_{12} \mathrm{H}_{20} \mathrm{O}_{10}$ & 323.0977 & 323.0984 & 2.2 \\
\hline 16 & Glu-Fru & $\mathrm{C}_{12} \mathrm{H}_{22} \mathrm{O}_{11}$ & 341.1083 & 341.1089 & 1.7 \\
\hline 17 & Glu-Fru $+\mathrm{H}_{2} \mathrm{O}$ & $\mathrm{C}_{12} \mathrm{H}_{24} \mathrm{O}_{12}$ & 359.1159 & 359.1195 & 10.0 \\
\hline 18 & $3 \times \mathrm{M}-4 \times \mathrm{H}_{2} \mathrm{O}$ & $\mathrm{C}_{18} \mathrm{H}_{24} \mathrm{O}_{12}$ & 431.1155 & 431.1195 & 3.9 \\
\hline 19 & $3 \times \mathrm{M}-3 \times \mathrm{H}_{2} \mathrm{O}$ & $\mathrm{C}_{18} \mathrm{H}_{26} \mathrm{O}_{13}$ & 449.1280 & 449.1301 & 4.6 \\
\hline 20 & $3 \times \mathrm{M}-2 \times \mathrm{H}_{2} \mathrm{O}$ & $\mathrm{C}_{18} \mathrm{H}_{28} \mathrm{O}_{14}$ & 467.1391 & 467.1406 & 3.2 \\
\hline 21 & $3 \times \mathrm{M}-\mathrm{H}_{2} \mathrm{O}$ & $\mathrm{C}_{18} \mathrm{H}_{30} \mathrm{O}_{15}$ & 485.1494 & 485.1512 & 3.7 \\
\hline 22 & $3 \times \mathrm{M}$ & $\mathrm{C}_{18} \mathrm{H}_{32} \mathrm{O}_{16}$ & 503.1597 & 503.1618 & 4.2 \\
\hline 23 & $3 \times \mathrm{M}+\mathrm{H}_{2} \mathrm{O}$ & $\mathrm{C}_{18} \mathrm{H}_{34} \mathrm{O}_{17}$ & 521.1698 & 521.1723 & 4.8 \\
\hline 24 & $4 \times \mathrm{M}-5 \times \mathrm{H}_{2} \mathrm{O}$ & $\mathrm{C}_{24} \mathrm{H}_{32} \mathrm{O}_{16}$ & 575.1613 & 575.1618 & 0.7 \\
\hline 25 & $4 \times \mathrm{M}-3 \times \mathrm{H}_{2} \mathrm{O}$ & $\mathrm{C}_{24} \mathrm{H}_{36} \mathrm{O}_{18}$ & 611.1798 & 611.1829 & 5.0 \\
\hline 26 & $4 \times \mathrm{M}-2 \times \mathrm{H}_{2} \mathrm{O}$ & $\mathrm{C}_{24} \mathrm{H}_{38} \mathrm{O}_{19}$ & 629.1903 & 629.1935 & 4.9 \\
\hline 27 & $4 \times \mathrm{M}-\mathrm{H}_{2} \mathrm{O}$ & $\mathrm{C}_{24} \mathrm{H}_{40} \mathrm{O}_{20}$ & 647.2013 & 647.2040 & 4.2 \\
\hline 28 & $4 \times M$ & $\mathrm{C}_{24} \mathrm{H}_{42} \mathrm{O}_{21}$ & 665.2129 & 665.2146 & 2.6 \\
\hline 29 & $4 \times \mathrm{M}+\mathrm{H}_{2} \mathrm{O}$ & $\mathrm{C}_{24} \mathrm{H}_{44} \mathrm{O}_{22}$ & 683.2243 & 683.2251 & 1.2 \\
\hline 30 & $5 \times \mathrm{M}-4 \times \mathrm{H}_{2} \mathrm{O}$ & $\mathrm{C}_{30} \mathrm{H}_{44} \mathrm{O}_{22}$ & 755.2228 & 755.2251 & 3.1 \\
\hline 31 & $5 \times \mathrm{M}-3 \times \mathrm{H}_{2} \mathrm{O}$ & $\mathrm{C}_{30} \mathrm{H}_{46} \mathrm{O}_{23}$ & 773.2323 & 773.2357 & 4.4 \\
\hline 32 & $5 \times \mathrm{M}-2 \times \mathrm{H}_{2} \mathrm{O}$ & $\mathrm{C}_{30} \mathrm{H}_{48} \mathrm{O}_{24}$ & 791.2478 & 791.2463 & 1.9 \\
\hline 33 & $5 \times \mathrm{M}-\mathrm{H}_{2} \mathrm{O}$ & $\mathrm{C}_{30} \mathrm{H}_{50} \mathrm{O}_{25}$ & 809.2536 & 809.2568 & 4.0 \\
\hline 34 & $5 \times M$ & $\mathrm{C}_{30} \mathrm{H}_{52} \mathrm{O}_{26}$ & 827.2645 & 827.2674 & 3.5 \\
\hline 35 & $5 \times \mathrm{M}+\mathrm{H}_{2} \mathrm{O}$ & $\mathrm{C}_{30} \mathrm{H}_{54} \mathrm{O}_{27}$ & 845.2775 & 845.2780 & 0.5 \\
\hline 36 & $6 \times \mathrm{M}-4 \times \mathrm{H}_{2} \mathrm{O}$ & $\mathrm{C}_{36} \mathrm{H}_{54} \mathrm{O}_{27}$ & 917.2748 & 917.2780 & 3.4 \\
\hline 37 & $6 \times \mathrm{M}-3 \times \mathrm{H}_{2} \mathrm{O}$ & $\mathrm{C}_{36} \mathrm{H}_{56} \mathrm{O}_{28}$ & 935.2860 & 935.2885 & 2.7 \\
\hline 38 & $6 \times \mathrm{M}-2 \times \mathrm{H}_{2} \mathrm{O}$ & $\mathrm{C}_{36} \mathrm{H}_{58} \mathrm{O}_{29}$ & 953.2968 & 953.2991 & 2.4 \\
\hline 39 & $6 \times \mathrm{M}-\mathrm{H}_{2} \mathrm{O}$ & $\mathrm{C}_{36} \mathrm{H}_{60} \mathrm{O}_{30}$ & 971.3095 & 971.3097 & 0.1 \\
\hline 40 & $6 \times M$ & $\mathrm{C}_{36} \mathrm{H}_{62} \mathrm{O}_{31}$ & 989.3201 & 989.3202 & 0.1 \\
\hline
\end{tabular}

$\mathrm{M}$ - designates monosaccharide, Glu—glucose and Fru fructose.

bottom left corner (IV) belongs to products with condensed heterocyclic ring structures after successive dehydration. Both heterocyclic condensed ring structures and disproporionation products appear as minor products in the mass spectrum at a concentration that does not allow further structural investigation by tandem MS. The second graphical technique, which we used to study the composition of caramelized disaccharides, was Kendrick type analyses. High resolution mass data obtained from TOF-MS experiments 

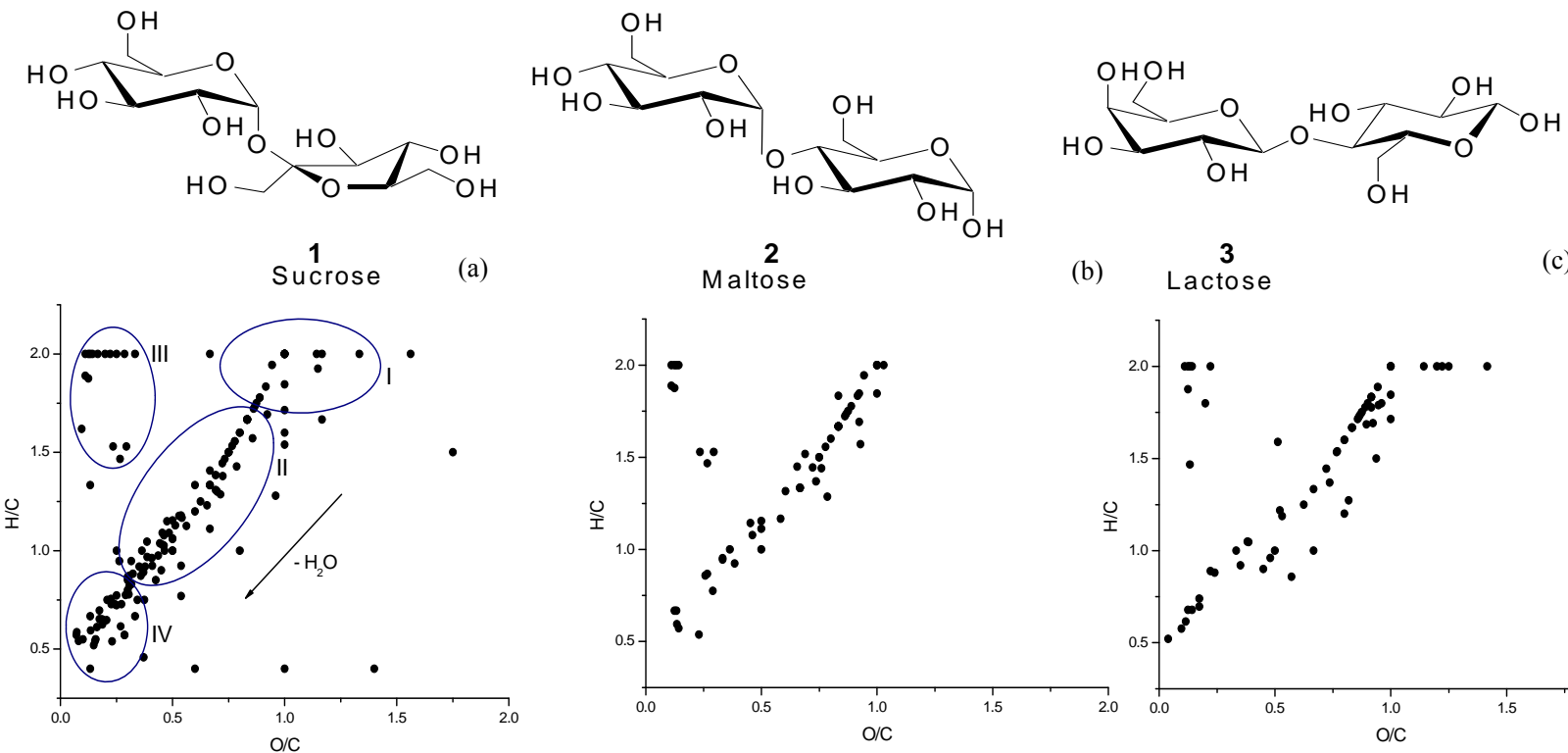

(b)
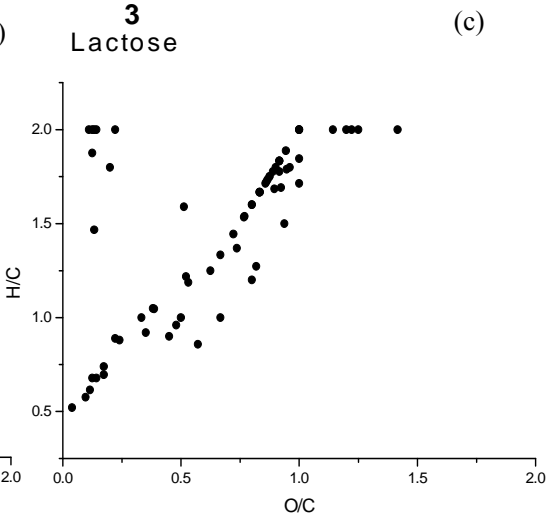

Fig. 2 Two dimensional van Krevelen plot (elemental ratio plot) showing the O/C ratio versus $\mathrm{H} / \mathrm{C}$ ratio for caramelized (a) sucrose, (b) maltose, (c) lactose in the negative ion mode in $\mathrm{m} / \mathrm{z}$ range between 50 and 1,200. I-carbohydrates; II-dehydrated products; III-disproportionation redox reactions products; IV-products with condensed heterocyclic ring structures after successive dehydration.

with Kendrick mass defect and nominal Kendrick mass values were recorded. The Kendrick plots were created with $\mathrm{H}_{2} \mathrm{O}$ increment as illustrated in Fig. 3. The compounds, which belong to the same homologous series, have identical Kendrick mass defect and lie on the horizontal lines in the graphs [31]. The plots of caramelized disaccharides possess some homologous series of the compounds. This type of graph showed the formation of oligomers with up to six monomeric hexoses in the case of heated disaccharides. Hydrated and dehydrated ions were visualized as well. Applied high-resolution mass spectrometry data interpretation techniques showed the whole range of products and reactions occurring during the heating procedure of disaccharides. In the following parts, the characterization of predominant products of caramelization of disaccharides will be disclosed.

\subsection{Characterization of Monomeric Hexoses}

In the direct infusion MS data for heated 1 and 2 strong peaks and for 3 a weak peak were apparent at $\mathrm{m} / \mathrm{z} 179.1$ corresponding to monomeric hexose units. LC-tandem MS experiments confirmed the monomeric hexoses as the $\alpha, \beta$ anomeric pairs for glucose 4 and fructose 5 for 1 , the $\alpha, \beta$ anomeric pairs for glucose 4 for 2 and the $\alpha, \beta$ anomeric pairs for glucose 4 and galactose 6 for 3, respectively (Fig. 4), by comparison of retention times and MS data with authentic reference standards. For example, for the ion at $m / z$ 179.1, a neutral loss of 18 as the base peak was observed, for heated 1 and 3 and a neutral loss of 90 as the base peak for 2 , which correspond to one water molecule and three formaldehyde molecules derived from the cross-ring cleavage, respectively. Presumably water as a reaction product of dehydration processes hydrolyses the disaccharides into their monomeric counterparts. For galactose, a dehydration process leading to a galactose based ion at $\mathrm{m} / \mathrm{z} 161.1$ is favoured (see later for detailed discussion). Epimerization was shown to be not observed for monomeric hexoses previously [23], as it has been reported in quinic acid and chlorogenic acid chemistry in food processing chemistry at identical temperatures $[32,33]$.

\subsection{Characterization of Oligomers of Hexoses}

$\mathrm{The} \mathrm{MS}^{\mathrm{n}}$ data of oligomers of hexose generated upon 


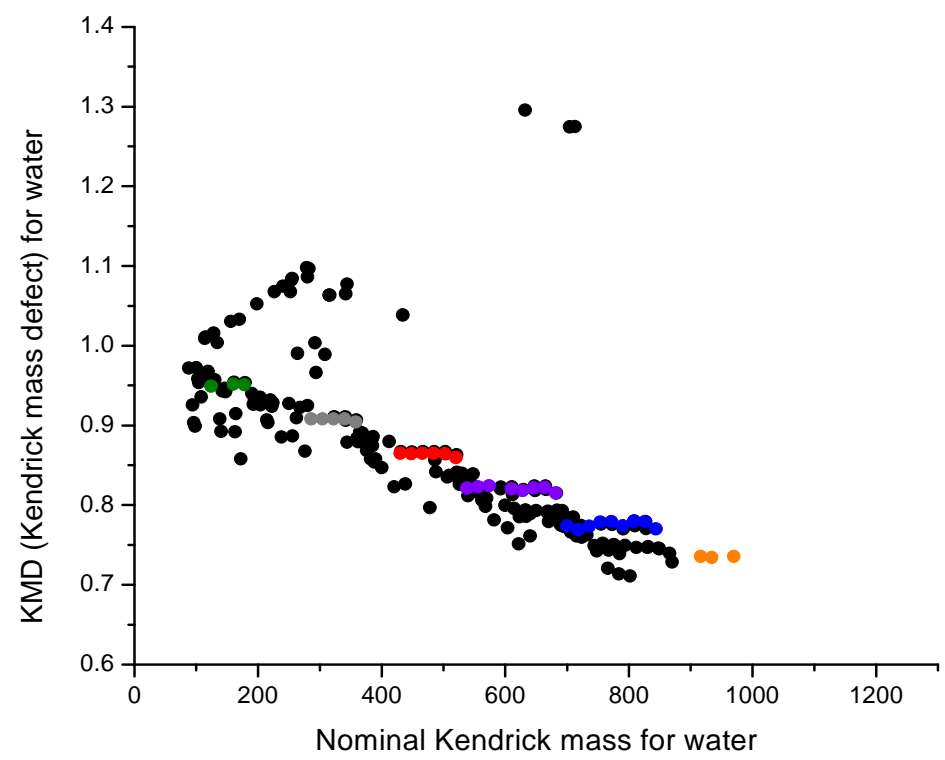

Fig. 3 Two dimensional Kendrick plot for mass increment $\mathrm{H}_{2} \mathrm{O}$ showing the distribution of the Kendrick mass defect plotted against the nominal Kendrick mass of pseudo-molecular ions for caramelized sucrose in the negative ion mode. The colors indicate formation of homologous series of monomers (green), dimers (gray), trimers (red), tetramers (violet), pentamers (blue), hexamers (orange).
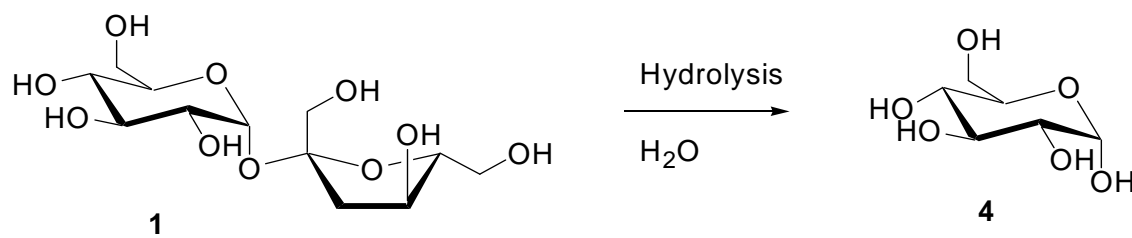

4

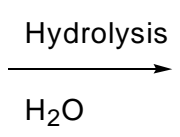

2<smiles>OC1OC2C(O)C(O)OC(C1O)C(O)C(O)C2O</smiles>

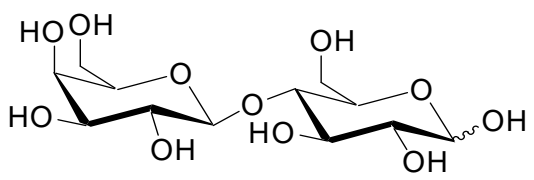

3

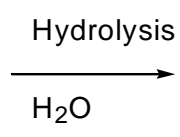

$\mathrm{H}_{2} \mathrm{O}$<smiles>OC[C@H]1O[C@H](O)[C@@H](O)[C@H](O)[C@H]1O</smiles><smiles>OC[C@H]1O[C@H](O)[C@@H](O)[C@H](O)[C@H]1O</smiles>

Fig. 4 Formation of monomeric hexoses from disaccharides 1-3 during heating. heating of 1,2 and 3 has been acquired in the negative ion mode using a direct infusion into ESI ion-trap mass spectrometer. Fragmentation of precursor ions of disaccharides $\left(\mathrm{C}_{12} \mathrm{H}_{22} \mathrm{O}_{11}\right)$ at $\mathrm{m} / z 341.1$ gave the main peaks at $m / z 178.9$ for heated sucrose, at $m / z 160.9$ for heated maltose and at $\mathrm{m} / \mathrm{z} 323.0$ for heated lactose. They came from the glycosidic bond cleavage between two monosacharides, which might occur in either one side or both sides of the bridging oxygen atom [34] and the removal of one water molecule.

Tandem LC-MS measurements under optimized chromatographic conditions revealed three resolved chromatopygraphic peaks in extracted ion chromatograms (EICs) at $m / z 341$ for heated 1 , one 
peak for heated 2 and two peaks for heated 3 . Hence for both heated maltose and lactose, the intact disaccharides are observed. For heated sucrose 1 in contrast hydrolysis into monomers occurs, followed by recombination to yield a third major disaccharides, whose similarity of the $\mathrm{MS}^{2}$ fragment spectra allows tentative assignment as a dimer of fructose $[35,36]$. Presumably fructose yields preferentially the more stable fructosyl cation, if compared to the glycosyl cation, serving as a glycosyl acceptor due to the increased number substituents at the $\mathrm{sp}^{2}$ carbon centre.

Disaccharides ions corresponding to oligomers containing three to six hexose units were observed at $\mathrm{m} / \mathrm{z} 503.2,665.2,827.3$ and 989.3 in the negative ion mode. The mass spectra of the precursor ion at $\mathrm{m} / \mathrm{z}$ 503.2, trimeric hexoses showed a neutral loss of 162 as the main peak for all studied caramel samples, arising from the cleavage of the glycosidic bond without bridging oxygen atom in the product ion. Tandem LC-MS investigations revealed in the EICs at $\mathrm{m} / \mathrm{z}$ of 503.2 twelve resolved chromatographic peaks for heated sucrose 1 (of which only six were sufficiently strong to provide $\mathrm{MS}^{n}$ data), and four resolved chromatographic peaks for maltose and lactose respectively (Fig. 5). Tentative reaction products are shown in Fig. 6.

It must be assumed that not all isomeric compounds can be chromatographically resolved here. The tandem MS fragment spectra and retention times for the four observed peaks for heated maltose 2 were identical to four $\mathrm{MS}^{2}$ spectra of caramelized glucose and have been tentatively assigned as trimers of glucose formed through non-selective glycosidic bond formation. A similar interpretation is suggested for heated lactose 3. For heated sucrose 1 three of the compounds identified resemble based on similarities of $\mathrm{MS}^{2}$ fragment spectra kestose or inulin type structures reported previously [35-37] with a saccharide sequence of Glu-Fru-Fru formed through non-selective glycosidic bond formation using the fructosyl cation intermediate. The other three peaks can be tentatively assigned as either Fru-Glu-Fru or Glu-Glu-Fru, for which no reference data are available (Fig. 6). The detailed regio- and stereochemistry of the reaction products remain open. It has to be noted that sucrose constitutes a special case among the disaccharides since the two anomeric centres are directly connected to one another and therefore sucrose can not act as a glycosyl acceptor directly.
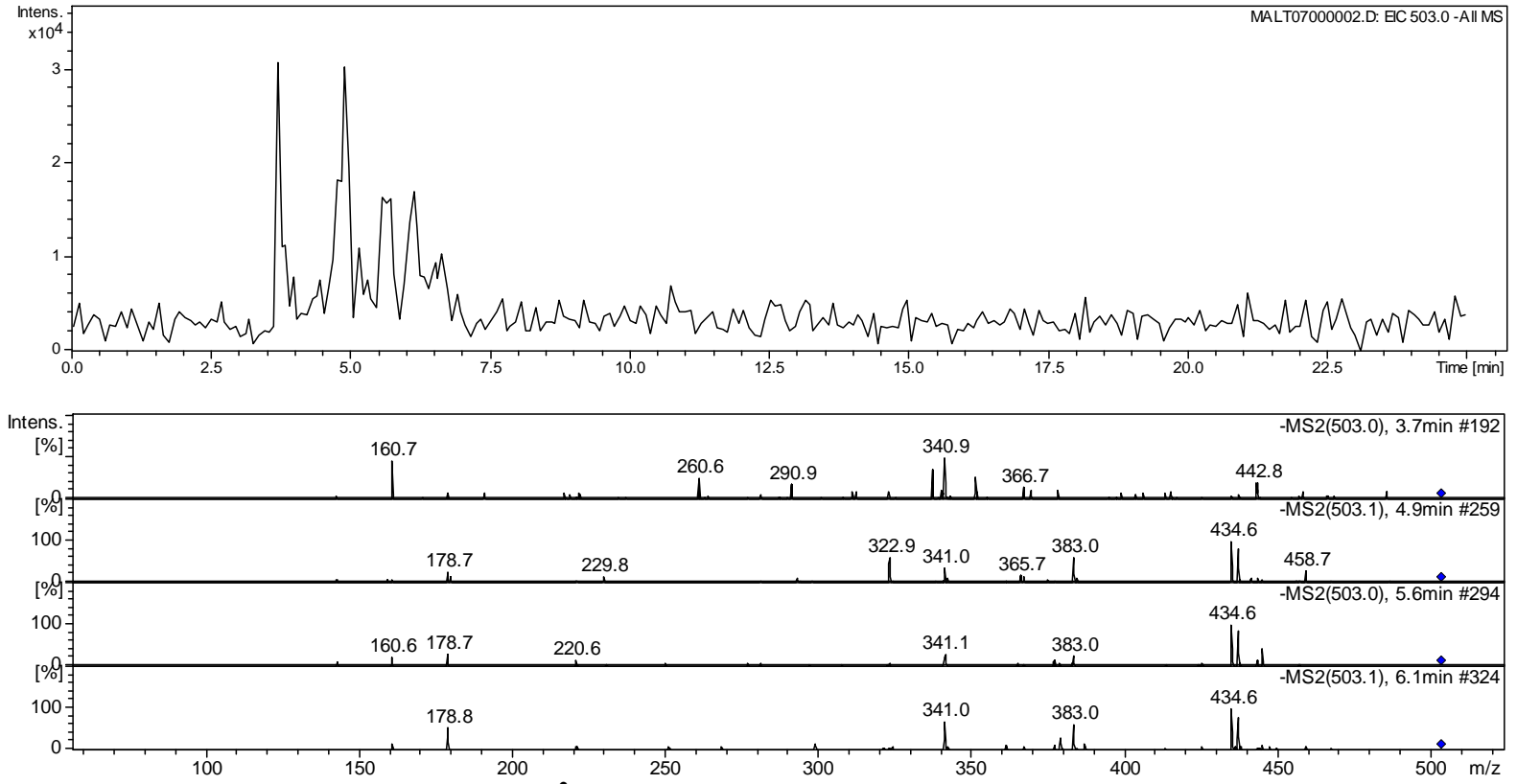

Fig. 5 Extracted ion chromatogram and $\mathrm{MS}^{2}$ spectra of pseudomelecular ion at $\mathrm{m} / \mathrm{z} 503.0\left(\mathrm{C}_{18} \mathrm{H}_{32} \mathrm{O}_{16}\right)$ for four selected chromatographic peaks of caramelized maltose in the negative ion mode. 
<smiles>OCC1(O)OC2(CO)OC(O)C(OC1O)C(O)C2O</smiles>

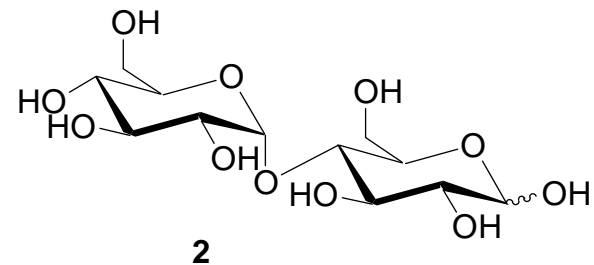

2

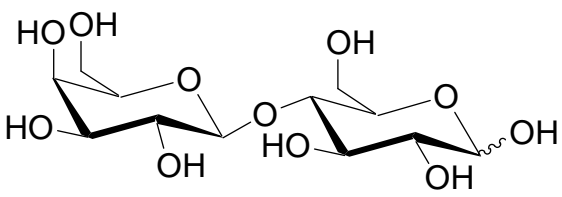

3

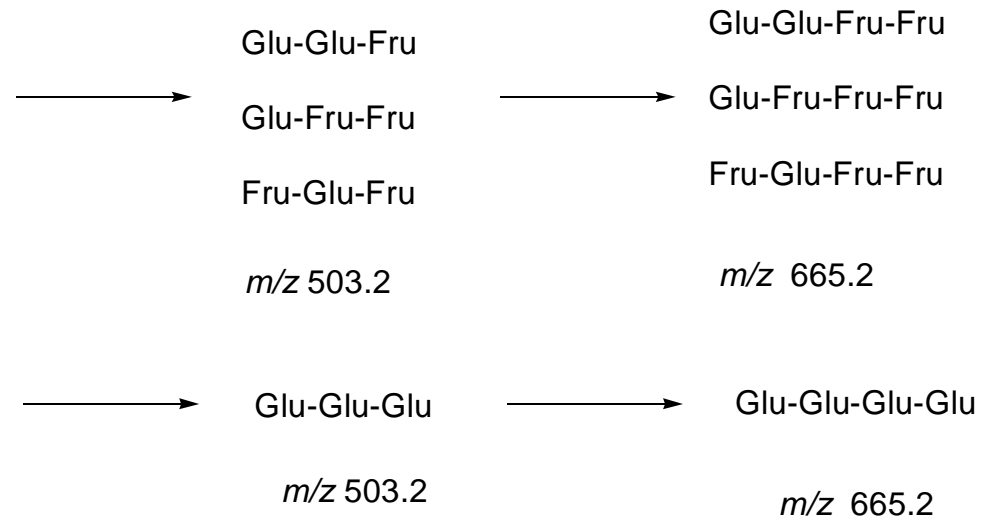

Gal-Glu-Glu

Glu-Glu-Glu

$\mathrm{m} / \mathrm{z} 503.2$
Tetrameric

hexoses

$m / z 665.2$

Fig. 6 Formation of oligomeric saccharides from 1-3 during heating (regio- and stereochemistry of oligosaccharides remains open).

$\mathrm{MS}^{2}$ spectra of the ion at $\mathrm{m} / \mathrm{z} 665.2$, tetramer of hexoses gave the most abundant fragment at $m / z 485$ of $(1,2)$ and at $\mathrm{m} / \mathrm{z} 503(3)$, indicated the cleavage of the external glycosidic bond with and without bridging oxygen atom in the product ion, respectively. A neutral loss of $162\left(\mathrm{C}_{6} \mathrm{H}_{10} \mathrm{O}_{5}\right)$ as the main peak for all studied caramel samples was present in $\mathrm{MS}^{2}$ spectra of the ion at $m / z$ 827.3, originating from the cleavage of the glycosidic bond in the external side of the molecule without bridging oxygen atom in the product ion, as it was observed for the aforementioned trimers of hexoses. $\mathrm{MS}^{2}$ spectrum of $m / z$ 989.3, a hexamer of glucose gave a base peak at $m / z 827(1,3)$, coming from the cleavage of the external glycosidic bond and at $m / z 665.2$ (2), coming from the cleavage of the internal glycosidic bond. Fragmentation studies of oligomeric ions of disaccharides in the negative ion mode for studied caramel samples are consistent with cleavages of glycosidic bonds on the external part of the molecules without and in rare cases with bridging oxygen atom. Targeted tandem-LC-MS measurements were carried out for all caramelized disaccharides and the extracted ion chromatograms (EICs) of oligomeric hexoses were generated. Each EIC showed various numbers of chromatographic peaks (see supplementary information).

\subsection{Characterization of Dehydration Products}

A direct infusion into ESI ion-trap mass spectrometer measurements in the negative ion mode has been performed for dehydrated monomers and oligomers, which were the major products of caramelized disaccharides.

Dehydrated monosaccharides were observed at $\mathrm{m} / \mathrm{z}$ 161.1 and tentative product structures 7 and 8 are shown in Fig. 7. Dehydrated disaccharides $\left(\mathrm{C}_{12} \mathrm{H}_{20} \mathrm{O}_{10}\right)$ were observed at $\mathrm{m} / \mathrm{z}$ 323.1. Fragmentation of such precursor ions gave the fragments at $m / z 160.9(1,2)$ and at $m / z 178.9$ (3). Both of them rose from the cleavage of the glycosidic bond leaving the bridging oxygen atom in the product ion and excluding the bridging oxygen atom in the product ion, respectively. The elimination of water molecule from glucose at C1-C4 positions forms an enol which tautomerises to its carbonyl form, as expected according to NMR and IR data analysis (Fig. 8). Moreover, monomeric hexoses 


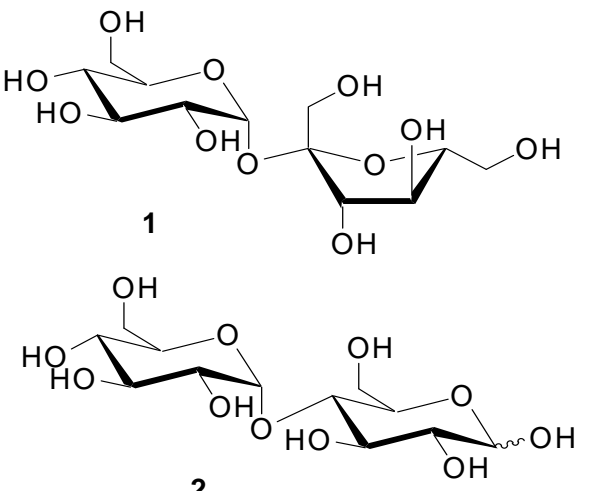

2

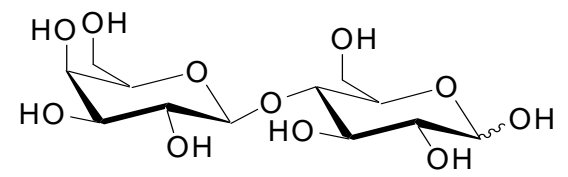

3
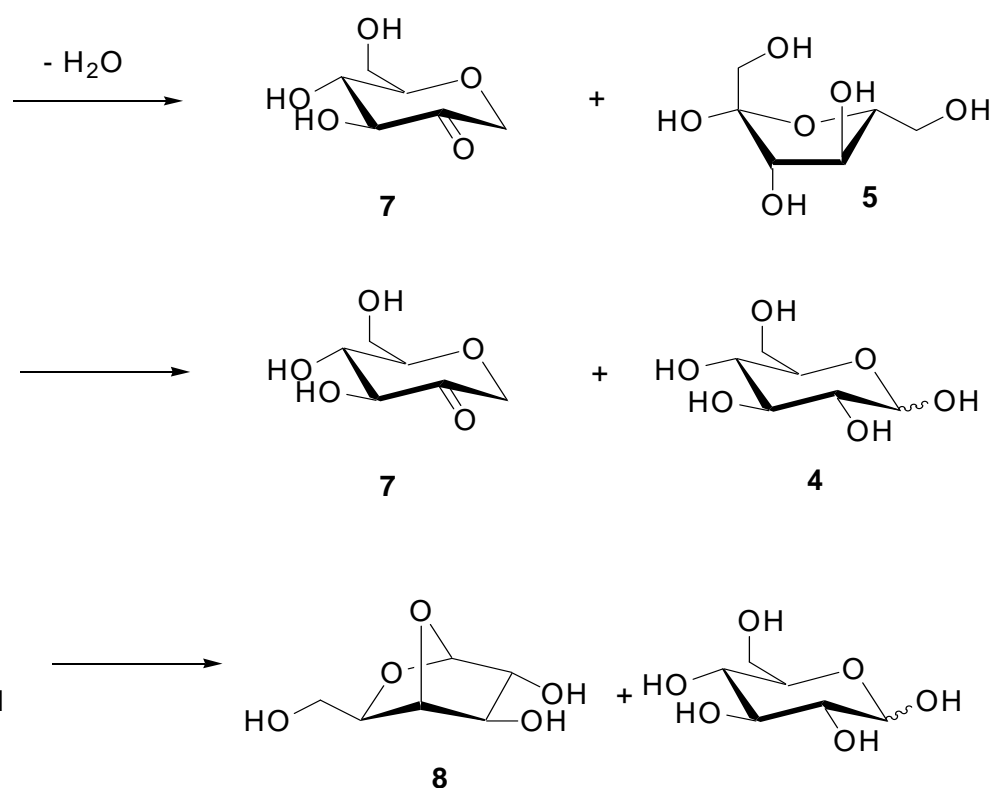

4

Fig. 7 Formation of dehydrated hexoses from heated disaccharides 1-3 (regiochemistry of water elimination was chosen randomly in 7).

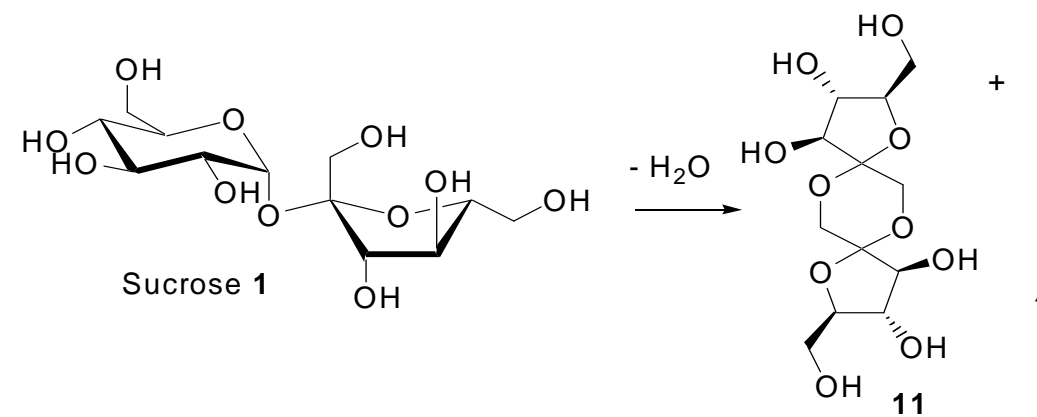

Difructosedianhydride

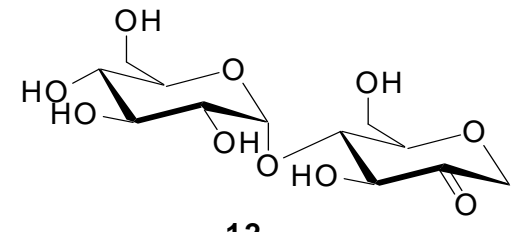

12

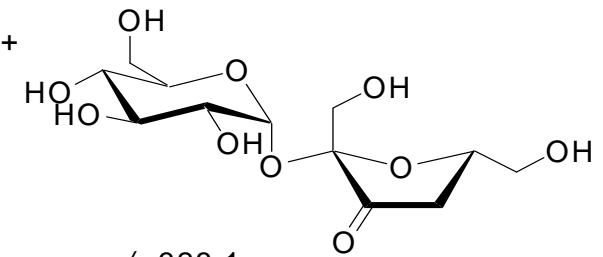

13
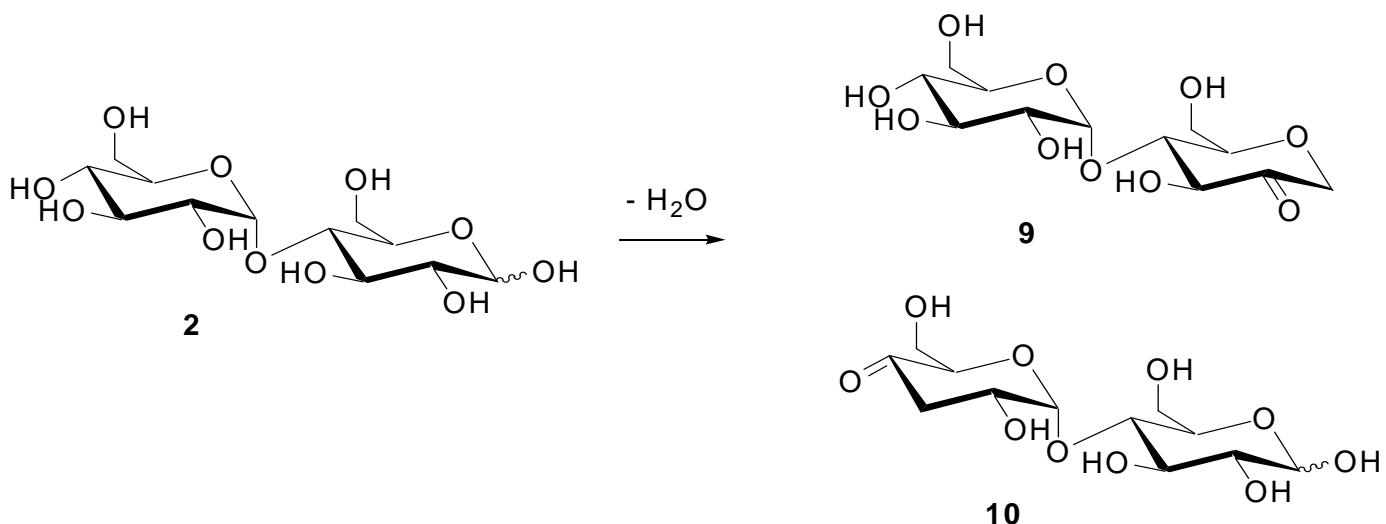

Fig. 8 Dehydration products of heated sucrose 1 and maltose (regiochemistry of water elimination was chosen randomly in 10-13). 
undergo dehydration reactions and product ions appeared at $m / z$ 161.1. Fragmentation data of this ion gave different main fragments for studied caramel samples, including the main fragment at $m / z 113(1,3)$ and 101 (2) arising from the cross-ring cleavage.

Dehydrated oligomers of caramel samples derived from a loss of a single water molecule were observed at $\mathrm{m} / \mathrm{z} 485.1,647.2,809.2$ and 971.3. The mass spectra of fragment ion 485 showed a loss of $162\left(\mathrm{C}_{6} \mathrm{H}_{10} \mathrm{O}_{5}\right)$ as the main peak for all caramels samples and derived from the cleavage of the glycosidic bond leaving the bridging oxygen atom in the product ion. Fragmentation of monodehydrated tetramers of hexoses at $\mathrm{m} / \mathrm{z} 647.2$ gave the main fragment at $\mathrm{m} / \mathrm{z} 485$ with a neutral loss of $162\left(\mathrm{C}_{6} \mathrm{H}_{10} \mathrm{O}_{5}\right)$ for 1 and 3 , arising from dehydrated dimers and at $\mathrm{m} / \mathrm{z} 467$ with a neutral loss of $180\left(\mathrm{C}_{6} \mathrm{H}_{10} \mathrm{O}_{5}\right)$ for $2 . \mathrm{MS}^{2}$ spectra of the ion $\mathrm{m} / \mathrm{z}$ 809.3, dehydrated pentamer of hexoses showed the main peak at $\mathrm{m} / \mathrm{z} 647$ and it is consistent for all analyzed samples with a neutral loss of $162\left(\mathrm{C}_{6} \mathrm{H}_{10} \mathrm{O}_{5}\right)$. $\mathrm{MS}^{3}$ spectra of an ion 485 gave the base peak at $\mathrm{m} / \mathrm{z}$ 323 for all analyzed samples. Fragmentation of monodehydrated hexamers of hexoses at $\mathrm{m} / \mathrm{z} 971.3$ gave the main fragment at $\mathrm{m} / \mathrm{z} 809.3$ with a neutral loss of $162\left(\mathrm{C}_{6} \mathrm{H}_{10} \mathrm{O}_{5}\right)$ for heated 1 and 3, arising from dehydrated dimers. The ion at $\mathrm{m} / \mathrm{z} 647$ with a neutral loss of $324\left(\mathrm{C}_{6} \mathrm{H}_{10} \mathrm{O}_{5}\right)$ is present as a main fragment of $\mathrm{MS}^{2}$ spectrum of an ion 971 for 2, coming from the cleavage of the second internal glycosidic bond. ESI-MS experiments with applied graphical techniques, showed the formation of dehydration products with one, two and three water molecules. Didehydrated disaccharide appeared at $\mathrm{m} / \mathrm{z} 305.1$ and followed didehydrated oligomers of hexoses at $\mathrm{m} / \mathrm{z} 467.1,629.2$, 791.2 and 953.3, respectively. When it was possible, fragmentation studies in the negative ion mode have been performed for mentioned ions and didehydrated pentamer of hexoses at $\mathrm{m} / \mathrm{z} 791.1$ of maltose gave in $\mathrm{MS}^{2}$ spectrum the main fragment at $\mathrm{m} / \mathrm{z} 449$ with a neutral loss of $342\left(\mathrm{C}_{12} \mathrm{H}_{22} \mathrm{O}_{11}\right)$, which correspond to the cleavage of the glycosidic bond. Although more intense peaks belong to dehydration reactions products with three water molecules, which appeared at 287.1 for disaccharides and 449.1, 611.2, 773.2, 935.3 for oligomers, respectively. $\mathrm{MS}^{2}$ spectra of the ion $\mathrm{m} / \mathrm{z} 287$ gave a neutral loss of $126\left(\mathrm{C}_{6} \mathrm{H}_{6} \mathrm{O}_{3}\right)$ as the main fragment for 1 . It could thus suggest the presence of hydroxymethylfurfural and supports the elimination of all three water molecules at one saccharide moiety. $\mathrm{MS}^{2}$ spectra of the ion $\mathrm{m} / \mathrm{z} 449.1$ gave ions 323.1 for all caramelized disaccharides with a neutral loss of 126 $\left(\mathrm{C}_{6} \mathrm{H}_{6} \mathrm{O}_{3}\right)$. This is consistent with the behavior of the aforementioned tridehydrated disaccharide showing the presence of hydroxymethylfurfural. Targeted tandem-LC-MS experiments have been performed for dehydrated products and resulted with their EICs. As an example, EIC of the ion at $\mathrm{m} / \mathrm{z} 161$ of an anhydro glucose in case of caramelized sucrose gave a total of 11 resolved chromatographic peaks, three of high, four of medium and four of low intensities. The formation of all 11 possible isomers of anhydro glucose could thus be explained. EICs of further dehydrated oligomers where generated and showed the formation of possible isomers. $\mathrm{MS}^{2}$ spectra of particular compounds showed an identical or different fragmentation pattern, and demonstrated non-selective formation of dehydrated oligomers of hexose.

Targeted tandem LC-MS measurements producing EICs of the ion at $\mathrm{m} / \mathrm{z} 323.1$ revealed 10 chromatographically resolved peaks for heated sucrose 1 , six for heated maltose 2 and 10 for heated lactose 3 (see supplementary information). For sucrose one chromatographic peak was showing retention time and $\mathrm{MS}^{2}$ spectra identical to difructosedianhydride 11, two compounds showed data resembling dehydration products 9,10 and 12 of heated maltose 2, as well previously observed for heated glucose [23]. The remaining seven signals showed tandem MS not previously observed and are tentatively assigned as dehydration products of sucrose loosing water at the fructose or glucose moiety. Similarly multiple peaks were observed in targeted LC-tandem MS experiments 
in EICs at $\mathrm{m} / \mathrm{z} 485.2$ and 647.2 (up to 16 resolved peaks). Hence, it can be concluded that non-selective loss of water from disaccharides generates a multitude of different carbonyl reaction products. At this point, it should be noted that such carbonyl reaction products generated during the heating of carbohydrates should be considered in Maillard type reactions with amino acids and peptides as electrophilic reagents.

\subsection{Characterization of Hydration Products}

Hydrated disaccharides appeared in the negative ion mode at $m / z$ 359.2. Hydrated products of further oligomers are also formed and were detected at $\mathrm{m} / \mathrm{z}$ $521.2,683.2,845.3$ and 1,007.3 in the negative ion mode. The observation of such hydration products is highly unusual and could alternatively be explained assuming the formation of non-covalent hydrated adducts. For this purpose we investigated a sample of beer containing various maltose derivatives under identical mass spectrometrical conditions [38]. These data show that hydrated oligomers are absent and should therefore be considered as genuine reaction products in caramel formation. Tandem MS data of mentioned ions showed similar fragmentation behavior of hydrated ions, which involves a loss of $36\left(2 \mathrm{H}_{2} \mathrm{O}\right)$, for example in $\mathrm{MS}^{2}$ spectrum of 359 and 521 the base peaks at $m / z 323$ and $\mathrm{m} / \mathrm{z} 485$ were observed, respectively. When it was possible, the $\mathrm{MS}^{3}$ spectra of precursor ions 323 and 521 were recorded to obtain the main peak with neutral losses of 162 coming from the cleavage of the glycosidic bonds. $\mathrm{MS}^{2}$ spectra of hydrated ions contained also the peaks with neutral losses of 180.1 which are consistent with hydration at any of anomeric centers producing an open chain hemiacetal structure. Analogously to oligomers and dehydration products targeted tandem-LC-MS experiments for all caramelized disaccharides were carried out and generating the extracted ion chromatograms (EICs) of hydrated ions. For example, EIC of hydratated disaccharide ion at $\mathrm{m} / \mathrm{z}$ 359.2 gave a total of 13 resolved chromatographic peaks, two of high, two of medium and nine of low intensities.
The multiple peaks for hydrated ions suggest the formation of isomeric structures.

\subsection{Comparison of Three Disaccharides}

In the previous section, we have described the identification of individual components formed in caramelization of disaacharides. In all three cases for sucrose, lactose and maltose, the same type of reaction products has been observed and classified mainly as oligomers and dehydration products. However, the three different mass spectra in Fig. 1 clearly show large variations in intensities of the individual ions pointing towards significant differences in the reaction kinetics observed in the three disaccharides. Therefore, we like to discuss in this section the main differences observed.

To graphically visualize differences in product formation, we decided to generate radar plots usually employed in sensory analysis. Within the plots, the individual ions are shown on the vertices, the relative intensity is shown on a scale from the center of the plot to its vertices and all three different disaccharides investigated are shown as colored lines within the plot. The first plot (Fig. 9a) shows difference in intensities of various oligomeric structures. The plot clearly shows that maltose favors oligomer formation followed by sucrose, whereas lactose is the most reluctant to form oligomers. The second plot (Fig. 9b) shows the relative intensities of various dehydrated ions. Here the opposite trend is apparent with lactose preferentially forming a monomeric dehydrated product at $m / z 161$. For higher molecular weight ions sucrose is more prone to dehydration followed by maltose. In the third plot (Fig. 9c), the ratio of intensities of oligomers versus dehydrated parent compounds is shown. Again for a monomeric hexose lactose displays the highest degree of dehydration followed by sucrose and finally maltose. For higher molecular weight derivatives the trend is reversed e.g., at $m / z 665 / 647$ or $827 / 809$ sucrose shows the highest degree of dehydration followed by maltose and finally lactose. The preferential formation of dehydrated monomers of lactose can be readily 


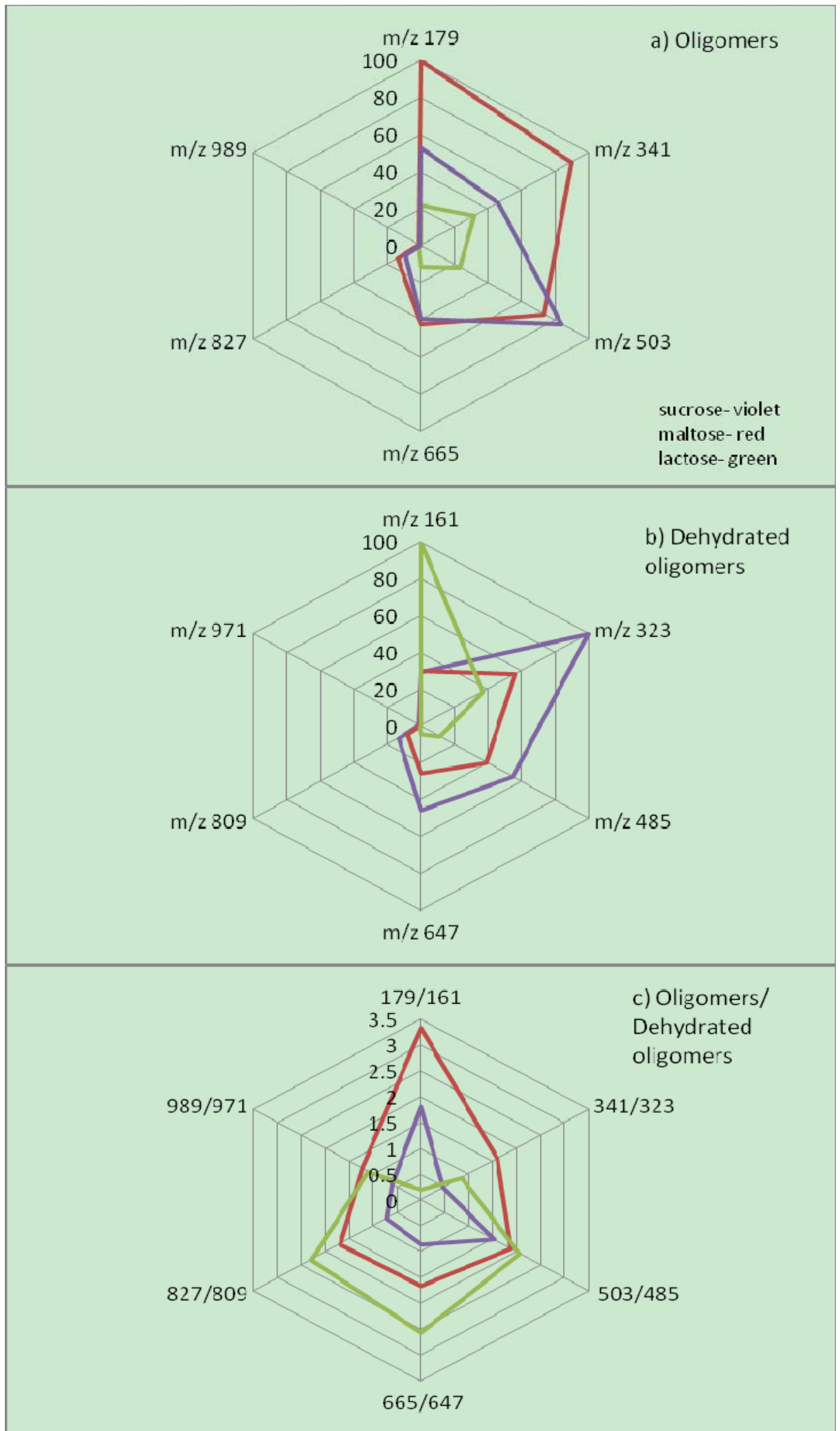

Fig. 9 Radar plots of classes of ions detected in direct infusion negative mode mass spectra of heated disaccharides 1-3 (a) oligomeric hexoses; (b) dehydrated oligomeric hexoses; (c) ratio of oligomeric to dehydrated hexoses (colored lines are coding samples 1-3). 
understood in terms of its stereochemistry. The axial 4-OH substituent in the galactose moiety of lactose allows for an intramolecular $\mathrm{S}_{\mathrm{N}}$ 2-like substitution reaction producing most likely a bicylic structure 8 (Fig. 7). The substitution can be classified according to Baldwin's rules as a 5-exo-tet cyclisation and is hence favored as demonstrated previously [39]. This fragmentation behavior has been previously proposed for galactose derivatives [40, 41]. This means as well that lactose readily breaks into its monosaccharide units at elevated temperatures, whereas as sucrose and maltose are thermally more stable. Dehydration at the disaccharide stage is favored for sucrose, which can be rationalized by assuming that the new olefinic double bond formed in a five membered ring furanose is favored over a double bond formed in a pyranose. Consecutive elimination of water yields an even more stable aromatic furan derivative.

\section{Conclusions}

In summary, we have solved the complexity of caramelized disaccharides including sucrose, maltose and lactose using advanced mass spectrometric techniques with novel data interpretation strategies. We described the majority of formed compounds and compared to each others. A high resolution mass spectrometry with fragmentation studies led to the assignment of formulas for around 40 compounds. Caramel formed from heated disaccharides consists of thousand of the compounds formed by a small number of unselective and chemoselective reactions. Oligomerization, dehydration and hydration reaction products are predominant. The oligomers of hexoses are created with up to eight carbohydrates unit through the unselective glycosidic bond formation. Monomeric hexoses are created with their dehydrated products as well. The fragmentation studies showed the similar behavior for studied disaccharides; therefore, novel data interpretation strategy such as van Krevelen and Kendrick plots are really useful to visualize a complex matrix like caramel. The work presented herein gives a valuable contribution to the complex composition of one of the most popular dietary material such as caramel.

\section{Acknowledgments}

The authors thank Jacobs Universtity Bremen and the Fond für Angewandte Umweltforschung des Landes Bremen for funding. Technical assistance by Ms. Anja Müller is gratefully acknowledged.

\section{Supporting Information Available}

Additional EICs, $\mathrm{MS}^{2}+\mathrm{MS}^{3}$ data of all compounds mentioned in the text, table of high resolution MS-TOF data for compounds identified, NMR and IR data. This material is free of charge via the Internet.

\section{References}

[1] L.W. Kroh, Caramelisation in food and beverages, Food Chem. 51 (1994) 373-379.

[2] O.G. Longe, Effect of boiling on the carbohydrate constituents of some non-leafy vegetables, Food Chem. 6 (1981) 1-6.

[3] A. Davidson, The Oxford Companion to Food, 3rd ed., Oxford University Press, Oxford, 2008.

[4] J.W. Lee, L.C. Thomas, J. Jerrell, H. Feng, K.R. Cadwallader, S.J. Schmidt, Investigation of thermal decomposition as the kinetic process that causes the loss of crystalline structure in sucrose using a chemical analysis approach (Part II), J. Agric. Food Chem. 59 (2011) 702-712.

[5] J.W. Lee, L.C. Thomas, S.J. Schmidt, Effects of heating on conditions on the glass transition parameters of amorphous sucrose produced by melt-quenching, J. Agric. Food Chem. 59 (2011) 3311-3319.

[6] A. Olano, N. Corzo, I.M. Castro, Changes in anomeric composition of different crystalline forms of lactose during thermal treatment, Food Chem. 14 (1984) 53-63.

[7] J.W. Lee, L.C. Thomas, S.J. Schmidt, Investigation of the heating rate dependency associated with the loss of crystalline structure in sucrose, glucose, and fructose using a thermal analysis approach (Part I), J. Agric. Food Chem. 59 (2011) 684-701.

[8] I. Blank, L.B. Fay, Formation of 4-hydroxy-2,5-dimethyl-3(2H)-furanone and 4-hydroxy-2(or 5)-ethyl-5(or 2)-methyl-3(2H)-furanone through Maillard reaction based on pentose sugars, J. Agric. Food Chem. 44 (1996) 531-536.

[9] A.I. Ruiz-Matute, M. Brokl, A.C. Soria, M.L. Sanz, I. 
Martínez-Castro, Gas chromatographic-mass spectrometric characterisation of tri- and tetrasaccharides in honey, Food Chem. 120 (2010) 637-642.

[10] C.P. Locas, V.A. Yaylayan, Isotope labeling studies on the formation of 5-(hydroxymethyl)-2-furaldehyde (HMF) from sucrose by pyrolysis-GC/MS, J. Agric. Food Chem. 56 (2008) 6717-6723.

[11] M. Manley-Harris, G.N. Richards, Di-D-fructose dianhydrides and related oligomers from thermal treatments of inulin and sucrose, Carbohydr. Res. 287 (1996) 183-202.

[12] C.O. Mellet, J.M.G. Fernández, Difructosedianhydrides (DFAs) and DFA-enriched products as functional foods, Top Curr.Chem. 294 (2010) 49-77.

[13] S. Kitaoka, K. Suzuki, Caramels and caramelization, Part I, The nature of caramelan, Agr. Biol. Chem. 31 (1967) 753-755.

[14] P. Mauri, M. Minoggio, P. Simonetti, C. Gardana, P. Pietta, Analysis of saccharides in beer samples by flow injection with electrospray mass spectrometry, Rapid Commun. Mass Spectrom 16 (2002) 743-748.

[15] G. Verado, I. Duse, A. Callea, Analysis of underivatized oligosaccharides by liquid chromatography/electrospray ionization tandem mass spectrometry with post-column addition of formic acid, Rapid Commun Mass Spectrom. 23 (2009) 1607-1618.

[16] B. Mulroney, J.C. Traegert, B.A. Stone, Determination of both linkage position and anomeric configuration in underivatized glucopyranosyl disaccharides by electrospray mass spectrometry, J. Mass Spectrom. 30 (1995) 1277-1283.

[17] D.J. Harvey, T.J.P. Naven, B. Küster, R.H. Bateman, M.R. Green, G. Critchley, Comparison of fragmentation modes for the structural determination of complex oligosaccharides ionized by matrix-assisted laser desorption/ionization mass spectrometry, Rapid Commun. Mass Spectrom. 9 (1995) 1556-1561.

[18] C. Hao, X. Ma, S. Fang, Z. Liu, S. Liu, F. Song, et al., Positive- and negative-ion matrix-assisted laser desorption/ionization mass spectrometry of saccharides, Rapid Commun. Mass Spectrom. 12 (1998) 345-348.

[19] I. Unterieser, J. Cuers, K. Voiges, J. Enebro, P. Mischnick, Quantitative aspects in electrospray ionization ion trap and matrix-assisted laser desorption/ionization time-of-flight mass spectrometry of malto-oligosaccharides, Rapid Commun. Mass Spectrom. 25 (2011) 2201-2208.

[20] J. Xue, L. Song, S.D. Khaja, R.D. Locke, C.M. West, R.A. Laine, et al., Determination of linkage position and anomeric configuration in Hex-Fuc disaccharides using electrospray ionization tandem mass spectrometry, Rapid Commun. Mass Spectrom. 18 (2004) 1947-1955.

[21] X. Zhu, T. Sato, The distinction of underivatized monosaccharides using electrospray ionization ion trap mass spectrometry, Rapid Commun. Mass Spectrom. 21 (2007) 191-198.

[22] I. Šimkovic, I. Šurina, M. Vričan, Primary reactions of sucrose thermal degradation, J. Anal. Appl. Pyrolysis. 70 (2003) 493-504.

[23] A. Golon, N. Kuhnert, Unravelling the chemical composition of caramel, J. Agric. Food Chem. 60 (2012) 3266-3274.

[24] A.S.P. Moreira, M.A. Coimbra, F.M. Nunes, J. Simões, M.R.M. Domingues, Evaluation of the effect of roasting on the structure of coffee galactomannans using model oligosaccharides, J. Agric. Food Chem. 59 (2011) 10078-10087.

[25] N. Hertkorn, M. Frommberger, M. Witt, B.P. Koch, P. Schmitt-Kopplin, P.E.M. Perdue, Natural organic matter and the event horizon of mass spectrometry, Anal. Chem. 80 (2008) 8908-8919.

[26] R.D. Gougeon, M. Lucio, M. Frommberger, D. Peyron, D. Chassagne, H. Alexandre, et al., The chemodiversity of wines can reveal a metabologeography expression of cooperage oak wood, Proc. Natl. Acad. Sci. 106 (2009) 9174-9179.

[27] N. Kuhnert, M.N. Clifford, A. Müller, Oxidative cascade reactions yielding polyhydroxy-theaflavins and theacitrins in the formation of black tea thearubigins: Evidence by tandem LC-MS, Food Funct. 1 (2010) 180-199.

[28] N. Kuhnert, J.W. Drynan, J. Obuchowicz, M.N. Clifford, M. Witt, Mass spectrometric characterization of black tea thearubigins leading to an oxidative cascade hypothesis for thearubigin formation, Rapid Commun. Mass Spectrom. 24 (2010) 3387-3404.

[29] N. Kuhnert, A. Golon, Untersuchung mittels Domino-Tandem-Massenspektrometrie, Deut Lebensm-Rundsch. 108 (2012) 148-152.

[30] Z. Wu, R.P. Rodgers, A.G. Marshall, Two- and three-dimensional van Krevelen diagrams: A graphical analysis complementary to the Kendrick mass plot for sorting elemental compositions of complex organic mixtures based on ultrahigh-resolution broadband Fourier transform ion cyclotron resonance mass measurements, Anal. Chem. 76 (2004) 2511-2516.

[31] C.A. Hughey, C.L. Hendrickson, R.P. Rodgers, A.G. Marshall, K. Qian, Kendrick mass defect spectrum: A compact visual analysis for ultrahigh-resolution broadband mass spectra, Anal. Chem. 73 (2001) 4676-4681.

[32] R. Jaiswal, M.H Dickman, N. Kuhnert, First dieasteros elective synthesis of methyl caffeoyl- and feruloyl-muco-quinates, Org. Biomol. Chem., 2012, DOI: $10.1039 / \mathrm{c} 2 \mathrm{ob} 25124 \mathrm{~h}$.

[33] R. Jaiswal, T. Sovdat, F. Vivan, N. Kuhnert, Profiling and 

Caramel Formed upon Heating of Disaccharides

characterization by LC-MS ${ }^{\mathrm{n}}$ of the chlorogenic acids and hydroxycin namoylshikimate esters in Maté (Ilex paraguariensis), J. Agric. Food Chem. 58 (2010) 5471-5484.

[34] R.E. March, C.J. Stadey, A tandem mass spectrometric study of saccharides at high mass resolution, Rapid Commun. Mass Spectrom. 19 (2005) 805-812.

[35] R.R. Seipert, M. Barboza, M.R. Ninonuevo, R.G. LoCascio, D.A. Mills, S.L. Freeman, et al., Analysis and quantitation of fructooligo saccharidesiusing matrix assisted laser desorption/ionization Fourier transform ion cyclotron resonance mass spectrometry, Anal. Chem. 80 (2008) 159-165.

[36] T. Visnapuu, A.D. Zzamfir, C. Mosonarca, M.D. Stanescu, T. Alamae, Fully automated chip-based negative mode nano electrospray mass spectrometry of fructooligo saccharides by heterologously expressed levansucrase from Pseudomonas ssyringae pv. tomato DC3000, Rapid Com. Mass Spectrom. 23 (2009) 1337-1346.

[37] M. Mantey-Harris, G.N. Richards, Formation of trisaccharides (kestoses) by pyrrolisis of sucrose, Carb. Res. 219 (1991) 101-103.
[38] B.H. Clower, E.D. Dodds, R.R. Seipert, C.B. Lebrilla, Dual polarity accurate mass calibration for electrospray ionization and matrix-assisted laser desorption/ionization mass spectrometry using maltooligo saccharides, Anal. Biochem. 381 (2008) 205-213.

[39] J. Eames, N. Kuhnert, F.H. Sansbury, S. Warren, Kinetic and thermodynamic control in the synthesis of tetrahydro-pyrans and furans from 1,4-diols by stereospecific phenylsulfanyl $(\mathrm{PhS})$ migration: Competition between exo and endo transition states and between $[1,2]$ and $[1,4]$ sulfanyl participation, Synlett 8 (1999) 1211-1214.

[40] O. Hernández-Hernandez, I. Calvillo, R. Lebrón-Aguilar, F.J. Moreno, M.L. Sanz, Hydrophilic interaction liquid chromatography coupled to mass spectrometry for the characterization of prebiotic galacto saccharides, J. Chromat. A 1220 (2012) 57-67.

[41] F. Cuyckens, A.A. Shahat, L. Pieters, M. Claeys, Direct stereochemical assignment of hexose and pentose residues in flavanoid O-glycosides by fast atom bombardment and electrospray ionization mass spectrometry, J. Mass Spectrom. 37 (12) (2002) 1272-1279. 